\title{
Research Paper: The Effect of Custom Made Foot Orthoses Fabricated With Medial Heel Skive Technique on Pain and Function in Individuals With Patellofemoral Pain Syndrome

Fateme Bahramian $^{1 *}$, Gholamreza Aminian¹, Masumeh Bagherzadeh ${ }^{2}$, Shima Fardipoor ${ }^{1}$, Vahabreza Kashani ${ }^{1}$

1. Department of Orthosis and Prosthesis, University of Social Welfare and Rehabilitation Sciences, Tehran, Iran.

2. Department of Orthosis and Prosthesis, Faculty of Rehabilitation, Iran University of Medical Sciences, Tehran, Iran.

\begin{tabular}{l|l}
$\begin{array}{c}\text { Use vour device to scan } \\
\text { and read the article online }\end{array}$ \\
Fabricated With Medial Heel Skive Technique on Pain and Function in Individuals With Patellofemoral Pain Syndrome. Iranian \\
Rehabilitation Journal. 2017; 15(1):37-42. https://doi.org/10.18869/nrip.irj.15.1.37
\end{tabular}

Article info:

Received: 16 Sep. 2016

Accepted: 23 Jan. 2017

\section{Keywords:}

Patellofemoral pain syndrome, Foot orthoses, Medial heel skive, Knee pain, Functional performance

\begin{abstract}
A B STRACT
Objectives: Patellofemoral pain syndrome (PFPS) is one of the significant causes of knee pain that results in reduced functional performance.Interventional foot orthotics may lead to improvement in symptoms. In this study, the effects of custom-made foot orthoses with medial heel skive technique on pain and functional performance after four weeks were evaluated.

Methods: Fourteen subjects with PFPS were given custom-made foot orthoses. The pain and function parameters were evaluated with a visual analog scale (VAS) and Kujala Patellofemoral Score (KPS) before the treatment and at four weeks follow-up.

Results: Significant improvements in pain was observed in participants with initial pain at four weeks $(\mathrm{P}<0.001)$. Also, an increased functional performance was seen in individuals with PFPS at four weeks $(\mathrm{P}<0.001)$.

Discussion: In this study, the custom-made foot orthoses with medial heel skive technique was found to be an effective conservative treatment to reduce the pain and improve the functional performance of patients with PFPS.
\end{abstract}

\section{Introduction}

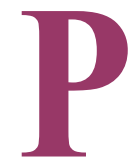

atellofemoral Pain Syndrome (PFPS) is one of the most significant causes of knee pain with a high prevalence in adolescents, especially in athletes such as runners [1]. PFPS is more common in overweight persons and women than in men [2-4]. PFPS accounts for $5 \%$ of all injuries and $25 \%$ of knee injury [3]. The commonly seen symptom include pain behind or around the patella that causes stress in the patellofemoral joint $[1,5]$. Pain in PFPS gets aggravated by running, ascending, and descending the stairs, squatting, and activities that involve knee flexion $[6,7]$. Risk factors of this disorder can be divided into intrinsic and extrinsic. Intrinsic risk factors include patella alta, patellar

* Corresponding Author:

Fateme Bahramian, PhD

Address: Department of Orthosis and Prosthesis, University of Social Welfare and Rehabilitation Sciences, Tehran, Iran.

Tel: +98 (912) 7330092

E-mail:fbahramian69@gmail.com 
hypermobility, and disorder of femoral articular surface. Extrinsic factors are more common and include trauma, muscle dysfunction, tight lateral restraints, poor quadriceps flexibility, and excessive subtalar pronation [5, 8]. Individuals with PFPS have reported pain and limitations in ability, functioning, and quality of life [5, 9]. According to some studies, the PFPS eventually leads to osteoarthritis [10, 11].

Several methods of treatment for PFPS include surgical and conservative methods. Physical therapy, patellar taping, patellofemoral bracing, and foot orthoses are classified under conservative treatment methods [5]. Foot orthoses are recommended to control excessive pronation of the subtalar joint during the stance phase of gait in subjects with PFPS. Previous studies also evaluated the effects of foot orthoses in knee pain and function [12-15]. A literature review in this field by Wolf Petersen reported limited evidence for the use of foot orthoses in patients with PFPS. Other studies investigating the effects of different types of foot orthoses have also demonstrated limited clinical and biomechanical evidence for wearing foot orthoses for the treatment of PFPS. Bonanno evaluated the effect of different depths of medial heel skive on plantar pressures but failed to provide any evidence related to the effect of foot orthoses with medial heel skive technique on pain and function. The medial heel skive technique, one of the modification methods, was developed for improving the ability of a foot orthosis to control excessive foot pronation [16]. So, the purpose of this study was to test the effectiveness of custom-made foot orthosis with medial heel skive technique in reducing patellofemoral pain and improving functional performance after four weeks.

\section{Methods}

\section{Subjects}

Fourteen females [age $($ mean $\pm S D)=23 \pm 2.18 \quad y$, height $($ mean $\pm S D)=163.43 \pm 5.68 \mathrm{~cm}$, and weight $($ mean \pm SD $)=57.29 \pm 5.48 \mathrm{~kg}]$ who were diagnosed with PFPS were recruited from Health centers. Inclusion criteria were as follows: 18-26 years of age; insidious onset of peripatellar or retropatellar knee pain; Pain provoked by at least two activities from running, walking, squatting, climbing and descending stairs, , and prolonged sitting; ability to walk without an assistive device; lack of neurological disorder and other disorders that affect the functionality; and lack of chondromalacia. Excessive foot pronation was also required for all subjects who were measured according to the procedures described by Tiberio [17]. Exclusion criteria were as follows: other knee pain source; knee ligament insufficiency; neurological and orthopedic impairment that affected early activities and functions; and previous knee surgery. For the purpose of this study, the subjects with PFPS were screened through physical examination by a therapist. The subjects were instructed to use the foot orthoses for 4 weeks and did not receive any concomitant treatment during the study period.

\section{Fabrication of the foot orthoses}

All foot orthoses used in the study were built in the Orthoses and Prothesis Department of Social Welfare and Rehabilitation Sciences in Tehran. By using the suspension technique, impressions of Plaster cast were collected for every subject [18]. In medial heel skive technique, the negative cast was made by a neutral suspension plaster cast as described by Root et al [18]. All the foot orthoses were made with polypropylene of $4.0 \mathrm{~mm}$ thickness from the heel to just behind the metatarsal heads. In the medial heel skive technique, once the positive cast was prepared from the negative cast, the first heels were divided into three parts and then a portion of the plantar medial heel of the positive cast ( $4 \mathrm{~mm}$ ) was removed. The medial aspect of the plantar heel was removed on a 15 degree angle until the marked depth has been reached at the medial thirds of the plantar heel. We considered a height of 18 $\mathrm{mm}$ for a lateral clip to reduce potential lateral slide and also rounded all edges so as to not cause any discomfort to the patients. The varus wedge created within the heel cup helps control pronation in subjects with PFPS [16].

\section{Procedure}

When the foot orthoses were made, the patients were asked to walk with them for a few minutes so as to report any discomfort. Once the foot orthoses were made, and before starting its use, the patients were asked to mark the pain perceived in the last week on a 10-cm VAS that ranged from 0 (no pain) to $10 \mathrm{~cm}$ (worst pain imaginable) [19]. They were also asked to answer the questions in Kujala Patellofemoral Scale (KPS) developed by Kujala [20]. The VAS is one of the best methods for evaluating the intensity of pain and has been reported to be a valid measure for detecting clinical changes in pain perception in individuals with PFPS $[21,22]$. The KPS consists of 13 items with discrete categories related to limp, weight bearing, walking, stairs, squatting, running, jumping, prolonged sitting with flexed knees, pain, swelling, painful patellar movements, thigh muscle atrophy, and flexion deficiency [23]. The participants were asked to return after 4 weeks of using foot orthoses so as to score the pain and function level. Each subject was 
asked whether they used any other form of treatment for knee pain during these 4 weeks. After 28 days of using the foot orthoses, the patients returned for follow-up and were again asked to indicate the pain perceived and answer the questions in KPS.

\section{Statistical analysis}

A blinded statistical analysis was performed. Data were screened for normality graphically and using the Kolmogorov-Smirnov statistics. According to the normality of data, a paired t-test was used to compare the pain and function in subjects with PFPS before and af- ter the intervention. Data were analyzed using the SPSS package (version 20.0). Differences were considered to be statistically significant if $\mathrm{P}<0.05$.

\section{Results}

\section{Pain and function}

A reduction in the VAS pain scores following 4 weeks of using the insoles with medial heel skive was shown in this study. As shown in Table 1, the mean pain following 4 weeks of insole use $(1.64 \pm 0.633)$ was significantly improved $(\mathrm{P}<0.001)$ compared to the baseline situation

Table 1. Mean \pm SD of pain and function at baseline and after 4 weeks of using foot orthoses with medial heel skive technique

\begin{tabular}{ccc}
\hline VAS Pain Score (Measured in Centimeters on a Sliding Scale) & \multicolumn{2}{c}{ KPS Score (Total) } \\
\hline Baseline & $3.93 \pm 0.073$ & $68.86 \pm 5.27$ \\
After 4 weeks of using insole & $1.64 \pm 0.633$ & $87.57 \pm 4.941$ \\
$P$ & $\leq 0.001$ & $\leq 0.001$ \\
\hline
\end{tabular}

Note: KPS: Kujala Patellofemoral Scale; VAS: Visual Analog Scale

Iranian Rehabilitation Journal

Table 2. Mean $\pm S D$ and $p$ value of Kujala Patellofemoral Score at baseline and after 4 weeks of using foot orthoses with medial heel skive technique

\begin{tabular}{|c|c|c|c|c|c|}
\hline & \multicolumn{2}{|c|}{ Baseline } & \multicolumn{2}{|c|}{ After 4 Weeks } & \multirow{2}{*}{$\mathbf{P}$} \\
\hline & Mean & Mean $\pm S D$ & Mean & Mean $\pm S D$ & \\
\hline Limp & 4.71 & 0.726 & 5.00 & 0.00 & 0.165 \\
\hline Weight bearing & 4.00 & 1.038 & 4.86 & 0.535 & $0.008^{*}$ \\
\hline Walking & 3.14 & 0.535 & 4.71 & 0.726 & $<0.001^{*}$ \\
\hline Stairs & 5.21 & 0.802 & 8.71 & 0.994 & $<0.001 *$ \\
\hline Squatting & 3.4 & 0.770 & 4.43 & 0.514 & $<0.001^{*}$ \\
\hline Running & 7.29 & 1.267 & 9.00 & 1.038 & $<0.001 *$ \\
\hline Limp & 8.50 & 1.557 & 8.93 & 1.492 & 0.165 \\
\hline Jumping & 4.43 & 1.158 & 8.29 & 0.726 & $<0.001^{*}$ \\
\hline $\begin{array}{l}\text { Prolonged sitting with flexed } \\
\text { knees }\end{array}$ & 4.29 & 2.164 & 8.57 & 0.938 & $<0.001^{*}$ \\
\hline Pain & 9.43 & 1.222 & 9.57 & 1.158 & 0.336 \\
\hline Swelling & 6.29 & 2.199 & 6.57 & 2.038 & 0.165 \\
\hline Thigh muscle atrophy & 4.83 & 0.38 & 4.58 & 0.51 & 0.082 \\
\hline Flexion deficiency & 3.14 & 0.535 & 3.57 & 0.938 & 0.082 \\
\hline Total & 68.86 & 5.27 & 87.57 & 4.941 & $\leq 0.001^{*}$ \\
\hline
\end{tabular}

*: $\mathrm{P}<0.05$ is meaningfull.

Iranian Rehabilitation Journal 
$(3.93 \pm 0.703)$. The mean total functional performance was also significantly improved following 4 weeks of using insole $(\mathrm{P}<0.001)$.

Data analyses indicated significant improvements in weight bearing after 4 weeks of using the insole with medial heel skive technique $(\mathrm{P}=0.008)$. Also, the subjects demonstrated significant improvements in walking, climbing and descending stairs, squatting, running, prolonged sitting with flexed knees, and pain at 4 weeks following the intervention $(\mathrm{P}<0.001)$. As shown in Table 2, the mean flexion deficiency following 4 weeks of insole with medial heel skive technique use $(4.00 \pm 1.038)$ was improved $(\mathrm{P}=0.008)$ compared to the baseline situation $(3.14 \pm 0.535)$ but it was not significant. The KPS scores for limping, jumping, thigh muscle atrophy, swelling and painful patellar movements were not significantly different at the 4-weeks follow-up compared to the baseline condition $(\mathrm{P}>0.05)$.

\section{Discussion}

Conservative treatment is usually considered as an initial approach in the management of individuals with PFPS, and the use of foot orthosis with medial heel skive technique is one of the conservative treatment methods. The results of this study have shown that the proposed conservative treatment reduced patellofemoral pain and improved the functional parameters considerably in the selected participants.

The main findings of this study was a significant reduction in the mean VAS pain scores following 4 weeks of foot orthoses use compared to the baseline situation. The function was also improved, indicating an increased ability in early functioning that may have been achieved. In this study, the use of custom mold foot orthoses with medial heel skive technique reduced knee pain by $58.26 \%$ and increased functional ability by $27.17 \%$, although the improvement of pain has been reported to increase by $34.19 \%$ using a prefabricated foot orthoses and $37.82 \%$ by using physiotherapy. In addition, functional index also increased by the use of prefabricated foot orthoses and physiotherapy by about $18 \%$ and $29 \%$, respectively [16].

A study by Barton showed that prefabricated foot orthoses marked an improvement in $11.6 \%$, and $30.2 \%$ reported moderate improvement in pain in single leg squat [12]. Reduction of pain may have produced these results and improved physical function. The improvements in function demonstrated in this study were similar to the findings of previous studies in this field using foot orthoses. Johnston et al demonstrated that custom fit foot or- thoses can improve the pain and functional performance They used the WOMAC method for the evaluation of pain [14] and function compared to the present study that used VAS and KPS.

There were certain limitations in this study. The participants wore the foot orthoses for only four weeks, and the study sample size was also small. In addition, only one type of foot orthoses was analyzed. However, future studies dealing with comparison between other designs of foot orthoses could prove beneficial to detect and compare effective conservative approaches in the treatment of patients with PFPS.

\section{Conclusion}

In this study, the foot orthoses with medial heel skive technique resulted in decreased pain and increased physical function in subjects with PFPS. Therefore, this type of foot orthoses may be used as an effective conservative method in improving the pain and function of patients with PFPS.

\section{Acknowledgments}

The article is extracted from Ms. Fateme Bahramian MSc. thesis in the department of orthotics \& prosthetics, University of Social Welfare and Rehabilitation Sciences.

\section{Conflict of Interest}

The authors declared no conflicts of interest.

\section{References}

[1] LaBella C. Patellofemoral pain syndrome: Evaluation and treatment. Primary Care: Clinics in Office Practice. 2004; 31(4):977-1003. doi: 10.1016/j.pop.2004.07.006

[2] Boling M, Padua D, Marshall S, Guskiewicz K, Pyne S, Beutler A. Gender differences in the incidence and prevalence of patellofemoral pain syndrome. Scandinavian Journal of Medicine \& Science in Sports. 2010; 20(5):725-30. doi: 10.1111/j.1600-0838.2009.00996.x

[3] Boling M, Padua D, Marshall S, Guskiewicz K, Pyne S, Beutler A. Gender differences in the incidence and prevalence of patellofemoral pain syndrome. Scandinavian Journal of Medicine \& Science in Sports. 2010; 20(5):725-30. doi 10.1111/j.1600-0838.2009.00996.x

[4] Peterson L, Renstrom P, Hope K. Sports injuries: Their prevention and treatment. Toms River: Ciba-Geigy; 1993. 
[5] Dixit S, Difiori JP, Burton M, Mines B. Management of patellofemoral pain syndrome. American Family Physician. 2007; 75(2):194-202. PMID: 17263214

[6] Enyley G, Dowd G. General orthopaedics current concepts of etiology and treatment of chondromalacia patellae. Clinical Orthopaedics and Related Research. 1984; (189):209-228. doi: 10.1097/00003086-198410000-00023

[7] Goodfellow J, Hungerford S, Woods C. Patellofemorial joint mechanics and pathology. 2. Chondromalacia patellae. Journal of bone and joint surgery. 58(3):291-9. PMID: 956244

[8] Lankhorst NE, Bierma-Zeinstra SMA, van Middelkoop M. Risk factors for patellofemoral pain syndrome: A systematic review. Journal of Orthopaedic \& Sports Physical Therapy. 2012; 42(2):81-94. doi: 10.2519/jospt.2012.3803

[9] Powers CM, Heino JG, Rao S, Perry J. The influence of patellofemoral pain on lower limb loading during gait. Clinical Biomechanics. 1999; 14(10):722-8. doi: 10.1016/s02680033(99)00019-4

[10] Myer GD, Ford KR, Barber Foss KD, Goodman A, Ceasar A, Rauh MJ, et al. The incidence and potential pathomechanics of patellofemoral pain in female athletes. Clinical Biomechanics. 2010; 25(7):700-7. doi: 10.1016/j.clinbiomech.2010.04.001

[11] Utting MR, Davies G, Newman JH. Is anterior knee pain a predisposing factor to patellofemoral osteoarthritis? The Knee. 2005; 12(5):362-5. doi: 10.1016/j.knee.2004.12.006

[12] Barton CJ, Menz HB, Crossley KM. The immediate effects of foot orthoses on functional performance in individuals with patellofemoral pain syndrome. British Journal of Sports Medicine. 2010; 45(3):193-7. doi: 10.1136/bjsm.2009.069203

[13] Eng JJ, Pierrynowski MR. Evaluation of soft foot orthotics in the treatment of patellofemoral pain syndrome. Physical therapy. 1993; 73(2):62-8. PMID: 8421719

[14] Johnston LB, Gross MT. Effects of foot orthoses on quality of life for individuals with patellofemoral pain syndrome. Journal of Orthopaedic and Sports Physical Therapy. 2004; 34(8):440-448. doi: 10.2519/jospt.2004.1384

[15] Munuera PV, Mazoteras-Pardo R. Benefits of custommade foot orthoses in treating patellofemoral pain. Prosthetics and Orthotics International. 2011; 35(4):342-9. doi: $10.1177 / 0309364611420201$

[16] Kirby K. The medial heel skive technique. Improving pronation control in foot orthoses. Journal of the American Podiatric Medical Association. 1992; 82(4):177-88. doi: 10.7547/87507315-82-4-177

[17] Tiberio D. The effect of excessive subtalar joint pronation on patellofemoral mechanics: A theoretical model. Journal of Orthopaedic \& Sports Physical Therapy. 1987; 9(4):160-5. doi: 10.2519/jospt.1987.9.4.160

[18] Root ML, Weed JH, Orien WP. Neutral position casting techniques. Los Angeles: Clinical Biomechanics Corporation; 1971.

[19] Bijur PE, Silver W, Gallagher EJ. Reliability of the visual analog scale for measurement of acute pain. Academic Emergency Medicine. 2001; 8(12):1153-7. doi: 10.1111/j.15532712.2001.tb01132.x
[20] Negahban H, Pouretezad M, Yazdi MJS, Sohani SM, Mazaheri M, Salavati M, et al. Persian translation and validation of the Kujala Patellofemoral Scale in patients with patellofemoral pain syndrome. Disability and Rehabilitation. 2012; 34(26):2259-63. doi: 10.3109/09638288.2012.683480

[21] Chesworth BM, Culham EG, Tata GE, Peat M. Validation of outcome measures in patients with patellofemoral syndrome. Journal of Orthopaedic \& Sports Physical Therapy. 1989; 10(8):302-8. doi: 10.2519/jospt.1989.10.8.302

[22] Thomeé R, Grimby G, Wright B, Linacre J. Rasch analysis of Visual Analog Scale measurements before and after treatment of Patellofemoral Pain Syndrome in women. Scandinavian Journal of Rehabilitation Medicine. 1995; 27(3):145-51. PMID: 8602476

[23] Kujala UM, Jaakkola LH, Koskinen SK, Taimela S, Hurme M, Nelimarkka O. Scoring of patellofemoral disorders. Arthroscopy: The Journal of Arthroscopic \& Related Surgery. 1993; 9(2):159-63. doi: 10.1016/s0749-8063(05)80366-4 
